\title{
Eficiência de materiais encapsulantes naturais e comerciais na liberação controlada de probiótico encapsulado
}

\author{
Efficiency of natural and commercial encapsulating materials \\ in controlled release of encapsulated probiotics
}

Autores | Authors

$\bowtie$ Elisa LAURENTI

Universidade Estadual de Londrina (UEL) Departamento de Ciência e Tecnologia de Alimentos Rodovia Celso Garcia Cid, PR 445 Km 380, Campus Universitário CEP: 86055-900 Londrina/PR - Brasil e-mail: elisalaurenti@zootecnista.com.br

Sandra GARCIA

Universidade Estadual de Londrina (UEL) Departamento de Ciência e Tecnologia de Alimentos Londrina/PR - Brasil e-mail:sgarcia@uel.br

Autor Correspondente / Corresponding Author

Recebido / Received: 30/03/2012 Aprovado / Approved: 08/05/2013 Publicado / Published: jun./2013

\section{Resumo}

O probiótico composto por Saccharomyces cerevisiae foi encapsulado pelo método de imobilização em cubos de ágar-ágar, em diferentes gomas comerciais e mucilagens, com o objetivo de proporcionar liberação controlada do microrganismo durante simulação gastrointestinal in vitro. Foram utilizados ágar-ágar (A-A), alginato (ALG), iota-carragena (I-CAR), goma arábica (ARA), taro (TARO), inhame (INH), linhaça (LIN) e quiabo (QUI) como materiais encapsulantes. Durante a simulação, foi realizada a contagem da levedura liberada das diferentes matrizes e a viabilidade do probiótico não encapsulado. Para analisar e diferenciar os tratamentos, foram obtidas imagens por microscopia eletrônica de varredura. As células não encapsuladas apresentaram viabilidade de $94 \%(p<0,05)$. Os tratamentos apresentaram a seguinte ordem crescente de liberação da levedura: $\mathrm{QUI}<\mathrm{LIN}<\mathrm{ALG}<\mathrm{INH}<\mathrm{ARA}<\mathrm{I}-\mathrm{CAR}<\mathrm{A}-\mathrm{A}<\mathrm{TARO}$. Através das microfotografias, não foi possível diferenciar os tratamentos, porém todos os materiais encapsulantes envolveram as leveduras, conferindo proteção física. No exterior da matriz de encapsulação, foi possível observar a presença de poros e fissuras, o que pode ter favorecido a difusão das células para o meio externo. Concluiu-se que a mucilagem de quiabo demonstrou ser um material encapsulante alternativo natural e mais eficiente do que as gomas comumente usadas no mercado.

Palavras-chave: Mucilagens; Leveduras; Encapsulação; Gomas; Hidrocoloides.

\section{Summary}

The probiotic composed of Saccharomyces cerevisiae was encapsulated by the method of immobilization in agar cubes, in order to provide a controlled release of the microorganism during simulated in vitro gastro-intestinal conditions (SGI). The following were used as encapsulating materials agar-agar (A-A), alginate (ALG), iota-carrageenan (I-CAR), gum Arabic (ARA), taro (TARO), yam (YAM), linseed (LIN) and okra (OKRA). A count was made of the yeast cells released from the different matrices during the simulation, and the viability of the non-encapsulated probiotic cells was also determined. Images were obtained by scanning electron microscopy to analyze and differentiate the treatments. The non-encapsulated cells showed $94 \%(p<0.05)$ viability. The treatments showed the following numerically increasing order of release of the yeast: OKRA $<L I N<A L G<Y A M<A R A<I-C A R<A$ $A<T A R O$. Treatments, could not be differentiated from the microphotographs, but, all the encapsulating materials coated the yeasts, providing physical protection. The presence of pores and cracks could be seen on the outside of the beads, witch may have favoured cell diffusion to the outside. The natural okra mucilage was shown to be the best alternative as an encapsulating material being more efficient than the commercial gums commonly found on the market.

Key words: Mucilages; Yeast; Encapsulation; Gums; Hydrocolloids. 


\section{Introdução}

O uso de biopolímeros tem apresentado um forte estímulo no mercado em razão das muitas possibilidades lucrativas para usos industriais e no mercado internacional (OKOJIE et al., 2010). A principal propriedade das gomas é a capacidade de se ligar com água, podendo atuar como aditivo em alimentos processados para modificar os componentes de textura e propriedades funcionais, com o objetivo de aprimorar a qualidade dos produtos finais (GLICKSMAN, 1969). A capacidade de ligação com a água faz dos carboidratos os materiais mais utilizados para encapsulação (DZIEZAK, 1988). Microencapsulação pode ser definida como um processo de empacotamento de materiais sólidos, líquidos ou gasosos em cápsulas extremamente pequenas, as quais podem liberar o conteúdo de forma controlada e sob condições específicas (FAVARO-TRINDADE et al., 2008). Vários estudos têm sido realizados com o objetivo de verificar o efeito benéfico da microencapsulação sobre a viabilidade das culturas probióticas, durante o armazenamento do produto e a passagem pelo trato gastrointestinal (RUIZ, 2011). A definição para probióticos comumente utilizada é a proposta por Fuller (1989), que os descreve como um suplemento alimentar constituído de microrganismos vivos, capazes de beneficiar o hospedeiro por meio do equilíbrio da microbiota intestinal. A levedura de canade-açúcar, Saccharomyces cerevisiae, pode ser utilizada como probiótico com excelência (PENNACCHIA et al., 2008; RAJKOWSKA e KUNICKA-STYCZYNSKA, 2010). Nas indústrias de álcool, em função da rápida velocidade de crescimento deste microrganismo, ocorre sempre o excesso de produção de levedura, que pode ser usada para os mais diversos fins depois de desidratada (GRANGEIRO et al., 2001). A resistência da levedura em ambientes críticos pode ser uma ótima ferramenta para pesquisas de liberação controlada do núcleo de microcápsulas, sob condições gastrointestinais simuladas, originando respostas mais precisas, uma vez que o microrganismo sobrevive em condições ambientais adversas e pode manter-se viável em todo período de avaliação de uma simulação gastrointestinal. O desprendimento das células durante a simulação pode ser avaliado sem que ocorram respostas subestimadas, pois as leveduras conseguem sobreviver durante todo o processo. Segundo Liserre et al. (2007), estudos sobre a sobrevivência de bactérias probióticas em soluções tampão podem levar a resultados errôneos, porque o potencial de sobrevivência pode ser subestimado. Ainda ressaltam que os resultados da literatura sobre a eficácia de encapsulamento para proteção de culturas probióticas são controversos e existe uma alta variação nos parâmetros avaliados, o que torna difícil a identificação do melhor procedimento de microencapsulação. O objetivo deste trabalho foi avaliar diferentes materiais encapsulantes naturais e comerciais na liberação controlada do probiótico encapsulado Saccharomyces cerevisiae sob condições gastrointestinais simuladas.

\section{Material e métodos}

\subsection{Microrganismo probiótico}

A levedura viável desidratada (Saccharomyces cerevisiae) foi obtida através do produto comercial Biosaf SC-47, produzido por Lesaffre - Saf Agri Brasil.

\subsection{Materiais encapsulantes comerciais}

Foram utilizados para a encapsulação Ágar-Ágar (Becton Dickinson \& Co.), Alginato de Sódio (Vetec), Goma Arábica (Sunset) e lota-Carragena (Griffit).

\subsection{Materiais encapsulantes naturais}

Foram extraídas mucilagens de inhame, taro, linhaça e quiabo, através da metodologia proposta por Lima (2007), e aplicadas como materiais encapsulantes. Cem gramas de cada produto foram mantidos em $500 \mathrm{~mL}$ de água destilada à temperatura ambiente por 2 horas e, após este período, completou-se o volume para um litro, removendo-se o resíduo com peneira fina para obter a mucilagem.

\subsection{Encapsulação do probiótico com mucilagens e gomas}

O método de encapsulação utilizado foi o de imobilização em cubos de ágar-ágar, adaptado do modelo proposto por Behera et al. (2010). Para cada processo de encapsulação, foi utilizado um volume total de $250 \mathrm{~mL}$ para todos os oito tratamentos, sendo estes descritos na Tabela 1.

O tratamento denominado 'A-A' foi considerado como controle dos processos de encapsulação, pois os demais tratamentos tinham como base o ágar-ágar na mesma concentração, porém eram adicionados de mucilagens ou gomas. Inicialmente, a solução composta por $4 \%$ (p/v) ágar-ágar e Tween-20 (1 mL. $\left.\mathrm{L}^{-1}\right)$, adicionada ou não de $1 \%$ (p/v) de gomas, foi esterilizada em autoclave por 15 minutos a $121^{\circ} \mathrm{C}$. O Tween-20 foi utilizado para aprimorar a permeabilidade da cápsula e, com isso, evitar a ruptura desta pelo $\mathrm{CO}_{2}$ produzido pelo microrganismo (CHANG et al., 1996). Após a esterilização, a solução foi mantida em banho-maria até atingir a temperatura de $42^{\circ} \mathrm{C}$, quando o $\mathrm{pH}$ foi ajustado para 6,6 com uma solução de $\mathrm{NaOH} 1 \mathrm{~N}$ ou $\mathrm{HCl} 1 \mathrm{~N}$, para que $10 \%(\mathrm{p} / \mathrm{v})$ do probiótico fosse adicionado e homogeneizado por 15 segundos através de um mixer (Philips RI1341). A mistura foi rapidamente vertida em um recipiente de acrílico $(20,5 \mathrm{~cm}$ $\times 14,5 \mathrm{~cm}$ ) e mantida sob refrigeração a $4{ }^{\circ} \mathrm{C}$ por 2 horas 
Eficiência de materiais encapsulantes naturais e comerciais na liberação controlada de probiótico encapsulado LAURENTI, E. e GARCIA, S.

Tabela 1. Relação dos tratamentos e suas composições.

\begin{tabular}{|c|c|c|c|c|c|}
\hline Tratamentos* & $\begin{array}{c}\text { Probiótico } \\
\text { (\%-p/v) }\end{array}$ & $\begin{array}{c}\text { Ágar-ágar } \\
(\%-p / v)\end{array}$ & $\begin{array}{c}\text { Água destilada } \\
(\mathrm{mL})\end{array}$ & $\begin{array}{l}\text { Gomas } \\
(\%-p / v)\end{array}$ & $\begin{array}{l}\text { Mucilagem } \\
(\mathrm{mL})\end{array}$ \\
\hline 1. Ágar-Ágar (A-A) & 10 & 4 & 250 & $x$ & $x$ \\
\hline 2. Alginato (ALG) & 10 & 4 & 250 & 1 & $x$ \\
\hline 3. Goma Arábica (ARA) & 10 & 4 & 250 & 1 & $x$ \\
\hline 4. lota-Carragena (ICAR) & 10 & 4 & 250 & 1 & $x$ \\
\hline 5. Mucilagem Inhame (INH) & 10 & 4 & $x$ & $x$ & 250 \\
\hline 6. Mucilagem Taro (TAR) & 10 & 4 & $x$ & $x$ & 250 \\
\hline 7. Mucilagem Quiabo (QUI) & 10 & 4 & $x$ & $x$ & 250 \\
\hline 8. Mucilagem Linhaça (LIN) & 10 & 4 & $x$ & $x$ & 250 \\
\hline
\end{tabular}

${ }^{*}$ Em todos os tratamentos foram adicionados $0,1 \%(p / v)$ de TWEEN-20.

para solidificar. O bloco obtido foi cortado igualmente em cubos de $5 \mathrm{~mm}^{3}$ por meio de um cortador manual. Os cubos foram redistribuídos novamente nos recipientes de acrílico e mantidos em estufa com circulação de ar a $45^{\circ} \mathrm{C}$ por 48 horas, para realizar a secagem, liberando todo o conteúdo de umidade incorporado.

\subsection{Liberação da levedura encapsulada sob condições gastrointestinais simuladas}

Para simular os sucos entéricos e gástricos, foi utilizada a metodologia proposta por Liserre et al. (2007). O probiótico encapsulado e livre foi analisado em relação a sua liberação das cápsulas e viabilidade, respectivamente, nas diferentes soluções tampão e tempos de avaliação. Assim, $10 \mathrm{~g}$ do probiótico, encapsulado ou não, foram incorporados em $90 \mathrm{~mL}$ de solução ácida ( $\mathrm{pH} 1,5)$ com pepsina $3 \mathrm{~g} \cdot \mathrm{L}^{-1}$ (Inlab) e lipase 0,9 mg. L ${ }^{-1}$ de Rhizopus oryzae (Sigma), e incubados a $37^{\circ} \mathrm{C}$ por 120 minutos, com agitação a $150 \mathrm{rpm}$. Posteriormente, o pH foi ajustado para 5,6 e adicionou-se pancreatina 1 g.L. $\mathrm{L}^{-1}$ (Inlab) e sais biliares ou Oxagall 10 g.L.-1 (Difco), com incubação a $37{ }^{\circ} \mathrm{C}$ por adicionais 120 minutos, sob agitação a $150 \mathrm{rpm}$. Por fim, o pH foi ajustado para 7,5 e as concentrações de pancreatina e sais biliares foram reajustadas para 1 g.L L $^{-1}$ e 10 g.L.-1, respectivamente, considerando-se o volume de solução alcalina adicionado ao sistema e incubado a $37^{\circ} \mathrm{C}$ por 120 minutos, com agitação a 150 rpm. Alíquotas foram removidas nos tempos 5, 30 e 120 minutos nos diferentes valores de $\mathrm{pH}$ para efetuar a contagem (UFC. $\mathrm{g}^{-1}$ ) de Saccharomyces cerevisiae liberadas das matriz de encapsulação.

\subsection{Contagem de Unidades Formadoras de Colônia (UFC) de S. cerevisiae por grama de amostra}

Para realizar a contagem Unidades Formadoras de Colônia (UFC) do probiótico livre e liberado das cápsulas, foi empregada metodologia proposta por Guillou et al. (2003). As alíquotas iniciais foram diluídas a concentrações apropriadas e semeadas em profundidade em ágar extrato de levedura glicose cloranfenicol (YGC) (Becton Dickinson \& Co.) e incubadas aerobicamente a $25{ }^{\circ} \mathrm{C}$ por 96 horas. Cada tratamento foi avaliado em triplicata, sendo que, para cada repetição, as diluições foram plaqueadas em duplicata para efetuar a média da contagem das colônias. A liberação ou a viabilidade foram representadas em porcentagem utilizando-se a Equação 1, prescrita por Pennacchia et al. (2008):

Liberação ou Viabilidade $(\%)=(\mathrm{Cf} / \mathrm{Ci}) \times 100$

em que: $\mathrm{Cf}=$ contagem (log UFC. $\mathrm{g}^{-1}$ ) após o processo; $\mathrm{Ci}=$ contagem (log UFC. $\left.\mathrm{g}^{-1}\right)$ antes do processo.

Para alcançar a contagem inicial das células contidas nas cápsulas, foi proposto homogeneizar as amostras previamente, triturando $5 \mathrm{~g}$ de amostra em $45 \mathrm{~mL}$ de água peptonada estéril $\left(45^{\circ} \mathrm{C}\right)$, utilizando-se um homogeneizador tipo turrax (Marconi, MA-102) por 30 segundos, como descreve Annan et al. (2008).

\subsection{Microscopia Eletrônica de Varredura (MEV)}

Para analisar a microestrutura das matriz de encapsulação, foi utilizada a metodologia proposta por Ainsley-Reid et al. (2005) com algumas modificações. As matriz de encapsulação foram fixadas em glutaraldeído $2 \%$ (p/v) em tampão fosfato $0,1 \mathrm{M} \mathrm{pH} \mathrm{7,2} \mathrm{por} \mathrm{uma} \mathrm{hora} \mathrm{em}$ temperatura ambiente, fraturadas em nitrogênio líquido e mantidas na mesma solução over night. No dia seguinte, foram submetidas a mais três lavagens de 15 minutos cada em tampão fosfato e, posteriormente, mantidas em solução de ósmio 1 \% (p/v) em tampão fosfato 0,1M pH 7.2 por uma hora sem iluminação, lavadas três vezes em tampão fosfato por 15 minutos cada e desidratadas gradualmente em etanol 70, 80, 90 e $100 \%$, por um período total de uma hora e 55 minutos. Por fim, as matriz de encapsulação mantidas em álcool 100 \% foram secas em ponto crítico (BAL-TEC, CPD 030), recobertas com ouro (BAL-TEC, SCD 050) e observadas em microscópio eletrônico de varredura (FEI QUANTA-200, Phillips) em alto vácuo e tensão de 20 kV. 


\subsection{Análise estatística}

Os resultados foram submetidos à análise de variância, seguida da comparação de médias pelo teste de Tukey a $5 \%$ de probabilidade, por meio do pacote computacional SISVAR (Sistema de Análise de Variância para Dados Balanceados).

\section{Resultados e discussão}

\subsection{Simulação gastrointestinal in vitro do probiótico não encapsulado}

No início do processo da digestão in vitro, quando o microrganismo é submetido a uma condição de pH extremamente ácida ( $\mathrm{pH} 1,5)$ e às enzimas (lipase e pepsina), a viabilidade diminuiu apenas 6,0 \%, mantendo a sobrevivência de $94 \%$ constante durante todo o processo, demonstrando que o microrganismo é resistente às condições gastrointestinais simuladas. $\mathrm{Na}$ passagem de $\mathrm{pH} 1,5$ para 5,6 , além da solução alcalina, são acrescentados sais biliares e pancreatina ao sistema, e nota-se que estatisticamente não houve diferença (Tabela 2). Portanto, é possível concluir que o principal fator que conferiu a queda de $6 \%$ na viabilidade do microrganismo na simulação gastrointestinal foi o pH ácido, pois o aumento do $\mathrm{pH}$ e a adição de sais biliares e enzimas (lipase, pepsina e pancreatina) não alteraram a contagem até o final do procedimento. O desempenho pode ser explicado pelo comportamento único de cada enzima nos determinados valores de $\mathrm{pH}$.

Rajkowska e Kunicka-Styczynska (2010) isolaram cepas Saccharomyces cerevisiae de kefir e fezes de frangos, e analisaram a sobrevivência das leveduras obtidas em condições gastrointestinais simuladas, comparando os resultados com cepas comerciais (Henterol $^{\circledR}$, Hamadin ${ }^{\circledR}$ e Omniflora ${ }^{\circledR}$ ) e algumas de coleção
(MYA-796 e MYA-797). A concentração de sais biliares $(0,1$ e $1 \%)$ não influenciou a viabilidade das cepas, sendo que todas foram resistentes por um período de 4 horas a $37^{\circ} \mathrm{C}$. Na simulação gastrointestinal, todos os tratamentos apresentaram resultados de viabilidade entre 75,5093,20 \% e 83,10-97,30 \% após 4 horas de incubação com pepsina (3 g. $\left.\mathrm{L}^{-1}\right)$ em pH 2,0 e pancreatina (1 g. $\left.\mathrm{L}^{-1}\right)$ em $\mathrm{pH} 8,0$, respectivamente. Com esses resultados, os autores concluíram que o pHé o fator que mais influencia na contagem das leveduras.

Pennacchia et al. (2008) isolaram 22 cepas de Saccharomyces cerevisiae de diferentes matrizes alimentícias (queijos, vinhos e embutidos cárneos curados) e determinaram, in vitro, a sobrevivência das leveduras após a passagem no trato gastrointestinal. A simulação inicial foi realizada em pH 2,5 por 2,5 horas a $37^{\circ} \mathrm{C}$ e as cepas alcançaram uma viabilidade média de 95,35 \%. Porém, quando adicionaram sais biliares (0,3\%) e pancreatina $(0,1 \%)$ à solução inicial, e incubaram por um período de 5 horas, apenas três cepas apresentaram sobrevivência maior que $90 \%$, indicando que a escolha da cepa é determinante na seleção de um microrganismo probiótico. De acordo com os resultados, é possível afirmar que a linhagem utilizada, Saccharomyces cerevisiae (Biosaf SC- $47^{\circledR}$ ), apresenta resistência, pois 94 \% de células estavam viáveis após a digestão simulada in vitro, isto é, a célula sobrevive ao pH ácido, aos sais biliares e às enzimas digestivas, indicando que a levedura irá alcançar o trato gastrointestinal inferior de forma quantitativa e qualitativa para contribuir positivamente no equilíbrio intestinal.

\subsection{Simulação gastrointestinal in vitro do probiótico encapsulado em gomas comerciais}

Os resultados de liberação dos tratamentos foram sintetizados na Tabela 3.

Tabela 2. Contagem (log) e viabilidade (\% \pm desvio padrão) do probiótico Saccharomyces cerevisiae não encapsulado após a digestão in vitro.

\begin{tabular}{|c|c|c|c|c|}
\hline $\begin{array}{c}\text { Contagem inicial } \\
(\log )\end{array}$ & pH & $\begin{array}{l}\text { Tempo } \\
\text { (min) }\end{array}$ & $\begin{array}{c}\text { Contagem final } \\
(\log )\end{array}$ & $\begin{array}{c}\text { Viabilidade } \\
\text { (\% } \% \text { DP) }\end{array}$ \\
\hline 9,18 & \multirow[t]{3}{*}{$1,5^{\star}$} & 5 & 8,63 & $94,00 \pm 1,16^{a}$ \\
\hline \multirow{8}{*}{$100 \%$ b } & & 30 & 8,50 & $92,64 \pm 1,82^{a}$ \\
\hline & & 120 & 8,53 & $92,99 \pm 2,66^{a}$ \\
\hline & \multirow[t]{3}{*}{$5,6^{*}$} & 125 & 8,57 & $93,44 \pm 2,43^{a}$ \\
\hline & & 150 & 8,51 & $92,79 \pm 2,23^{a}$ \\
\hline & & 240 & 8,56 & $93,31 \pm 2,03^{a}$ \\
\hline & \multirow[t]{3}{*}{$7,5^{*}$} & 245 & 8,37 & $91,23 \pm 1,69^{a}$ \\
\hline & & 270 & 8,45 & $92,10 \pm 2,06^{a}$ \\
\hline & & 360 & 8,63 & $94,00 \pm 3,01^{a}$ \\
\hline \multicolumn{3}{|c|}{ Média de viabiliadade $(\mathrm{CV}=2,44 \%)$} & & 93,65 \\
\hline
\end{tabular}

abc Valores acompanhados por letras diferentes são significativamente diferentes entre si $(\mathrm{p}<0,05) .{ }^{*} \mathrm{pH} 1,5$ (pepsina $3 \mathrm{~g} . \mathrm{L}^{-1}$ e lipase 0,9 mg. $\left.\mathrm{L}^{-1}\right)$, $\mathrm{pH}$ 5,6 (pancreatina $1 \mathrm{~g} \cdot \mathrm{L}^{-1}$ e oxgall $10 \mathrm{~g} \cdot \mathrm{L}^{-1}$ ), $\mathrm{pH}$ 7,5 (pancreatina $1 \mathrm{~g} \cdot \mathrm{L}^{-1}$ e oxgall $10 \mathrm{~g} \cdot \mathrm{L}^{-1}$ ). 


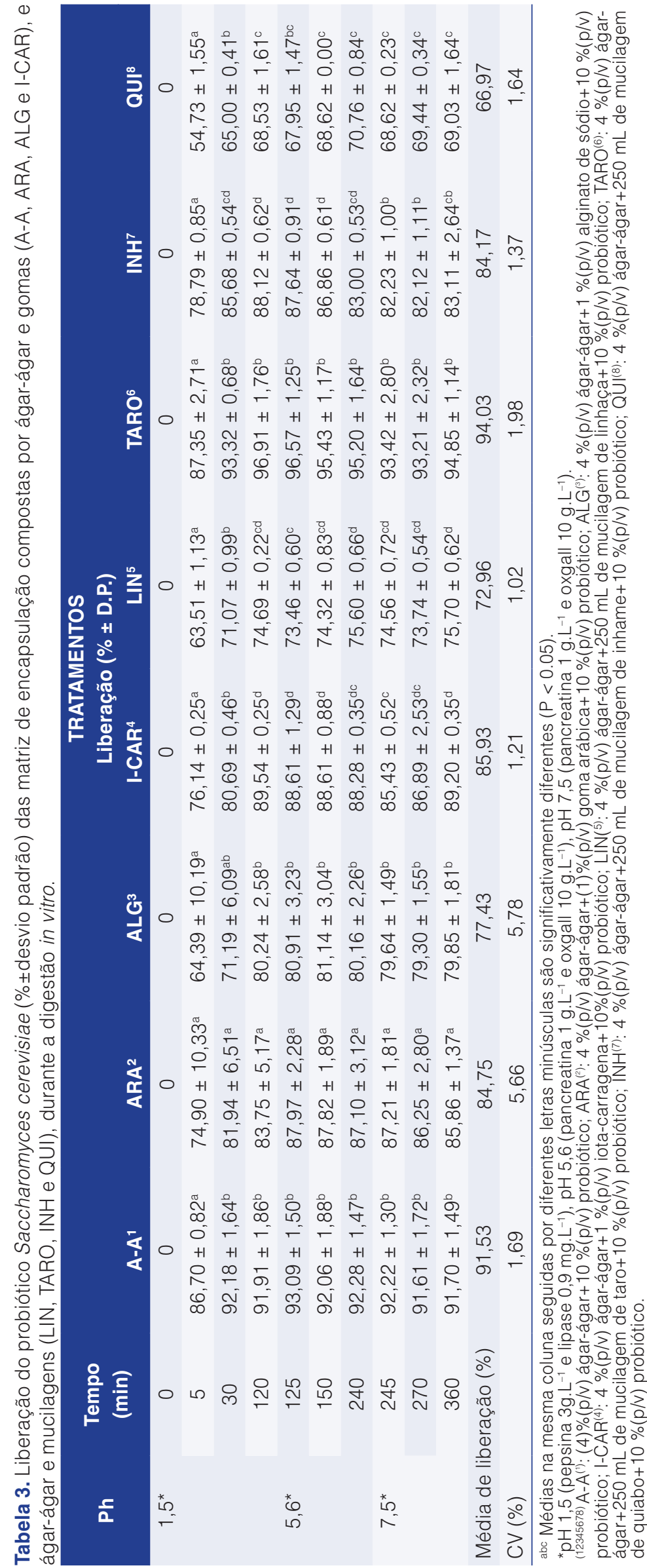


- Digestão in vitro do probiótico encapsulado em ágar-ágar (A-A). Assim que as cápsulas foram submetidas à solução ácida com enzimas, as células do interior da matriz de encapsulação foram gradualmente liberadas para o meio externo e, por essa razão, a liberação é menor no início do processo da simulação gastrointestinal e aumenta até atingir estabilidade, como demonstrado na Tabela 3. Os resultados da simulação apresentaram diferenças estatísticas a partir do tempo 30 minutos em pH 1,5, indicando que seria liberado $92 \%$ do conteúdo encapsulado no trato gastrointestinal superior, a fase mais crítica da digestão. Portanto, até o final do processo, aproximadamente $8 \%$ do conteúdo encapsulado continua aprisionado na matriz de encapsulação, apontando que o ágar-ágar não é um material encapsulante adequado para conferir liberação controlada. Frente a esses resultados, é possível afirmar que o fator determinante para a liberação dos microrganismos da matriz em questão é o ácido, primeiro contato da cápsula no início da digestão, pois, mesmo com o aumento do $\mathrm{pH}$ e do tempo de avaliação, o percentual de liberação da cápsula continua constante até o término do processo. Segundo Glicksman (1969), a sensibilidade das cápsulas de ágarágar ao meio ácido pode ser explicada pela diminuição da força de gel, que pode ser intensificada com o decréscimo do $\mathrm{pH}$.

- Digestão in vitro do probiótico encapsulado em ágar-ágar e goma arábica (ARA). Não foram observadas diferenças estatísticas $(p>0,05)$ na liberação de células neste tratamento, como observado na Tabela 3. O comportamento de liberação foi distinto quando comparado ao tratamento controle, pois as células se difundiram para o meio externo até atingir a estabilidade em pH 5,6 no tempo 5 minutos, enquanto o tratamento controle atingiu o seu pico máximo de liberação no tempo 30 minutos em $\mathrm{pH} 1,5$. O material encapsulado não foi eficientemente aprisionado durante a simulação gastrointestinal, pois apenas $15 \%$ do conteúdo encapsulado estava retido na extensão da matriz de encapsulação, ainda que $7 \%$ a mais quando comparado ao controle. Desmond et al. (2002) encapsularam, por coacervação complexa, o microrganismo Lactobacillus paracasei NFBC 338 em leite desnatado reconstituído (10 \% $\mathrm{p} / \mathrm{v})$ e goma acácia (10 \% p/v), e avaliaram a resistência da cápsula quando exposta ao suco gástrico porcino $(\mathrm{pH} 3,0)$ a $37{ }^{\circ} \mathrm{C}$ por 120 minutos. Os autores afirmam que as cápsulas foram mais resistentes durante a simulação em suco gástrico porcino, quando comparadas às células encapsuladas sem a goma (controle). Porém, a sobrevivência ainda foi muito baixa em razão da sensibilidade do microrganismo ao pH ácido.

- Digestão in vitro do probiótico encapsulado em alginato de sódio (ALG). A Tabela 3 apresenta diferenças estatísticas $(p<0,05)$ apenas no início do processo. O comportamento de liberação foi gradual, atingindo o seu pico de liberação no tempo 120 minutos em pH 1,5, diferente do tratamento controle, que atingiu o pico no tempo 30 minutos do mesmo pH. Além da característica de liberação controlada, a goma também favoreceu a retenção do microrganismo na cápsula, demonstrando ser uma opção eficiente como material encapsulante. A maior retenção da levedura em alginato de sódio pode ser explicada pela característica da goma em formar géis sob condições ácidas (GLICKSMAN, 1969). Outro fator é a habilidade de torna-se solúvel e viscosa, quando submetida ao alto $\mathrm{pH}$ do trato gastrointestinal. Este comportamento dependente do $\mathrm{pH}$ pode ser explorado para perfis de liberação controlada do núcleo (GEORGE e ABRAHAM, 2006). Liserre et al. (2007) submeteram cápsulas de Bifidobacterium animalis subsp. lactis obtidas por extrusão em alginato $2 \%(p / v)$, sob as mesmas condições gastrointestinais in vitro desempenhadas neste projeto e concluíram que a encapsulação favoreceu a sobrevivência do microrganismo quando comparada à das células não encapsuladas. $O$ alginato de sódio reteve, em média, $22,57 \%$ dos microrganismos dentro da matriz de encapsulação, aproximadamente $15 \%$ mais eficiente em relação ao tratamento controle, que aprisionou apenas $8 \%$ do material encapsulado, demonstrando assim aprimorar as características de liberação controlada.

- Digestão in vitro do probiótico encapsulado em iota-carragena (I-CAR). A matriz de encapsulação com iota-carragena reteve $14 \%$ do material encapsulado, um valor $6 \%$ mais alto quando comparado ao tratamento controle, que aprisionou $8 \%$ das células no interior da matriz de encapsulação. A liberação da levedura para o meio externo foi gradual até o tempo 120 minutos em $\mathrm{pH} 1,5$ e manteve a mesma contagem até o fim do procedimento (Tabela 3). Ding e Shah (2009) microencapsularam, por emulsão, microrganismos do gênero Lactobacillus 


\begin{abstract}
e Bifidobacterium em $3 \%$ de carragena, e avaliaram a liberação das células em pH 2,0 por 120 minutos. Depois de decorridos 30 minutos do processo, os valores de liberação das células para o meio externo estiveram entre $79,23 \%$ e $85,55 \%$. Apesar do valor superior na retenção das leveduras, a iota-carragena promoveu a liberação de $86 \%$ do agente ativo encapsulado, demonstrado não ser indicado como material de parede neste sistema.
\end{abstract}

\subsection{Digestão in vitro do probiótico encapsulado em mucilagens}

As mucilagens como materiais encapsulantes são produtos inovadores e, portanto, não são encontrados artigos para comparações. As cápsulas contendo mucilagem de linhaça em sua composição demonstraram ser uma nova fonte de material encapsulante eficiente, pois liberaram, em média, $73 \%$ do conteúdo inicial incorporado, isto é, mantiveram $27 \%$ do material encapsulado no interior da matriz, representando uma melhora de aproximadamente $18 \%$ na retenção das células, quando comparadas ao tratamento controle. A difusão das células para o meio externo foi gradual, alcançando o valor mais alto de liberação em pH 1,5 no tempo 120 minutos e manteve-se constante até o término da simulação gastrointestinal. Portanto, além da característica de liberação controlada, a mucilagem de linhaça também conferiu eficiência na retenção das células no interior da matriz de encapsulação durante a digestão in vitro. O tratamento que apresentou os maiores valores de liberação, quando comparados todos os tratamentos, foi com a utilização da mucilagem de taro. Estatisticamente $(p<0,05)$, houve diferença apenas entre o pH 1,5 no tempo 5 minutos em relação aos outros períodos da simulação gastrointestinal. Supõe-se que algum composto da mucilagem possa ter prejudicado as características físico-químicas do ágar-ágar, para que possa ser explicado o resultado inferior ao controle. Nenhuma razão aparente foi encontrada na literatura. A liberação média das leveduras encapsuladas para o meio externo foi de $94,00 \%$, mantendo aprisionado apenas $6,00 \%$ do material encapsulado durante o processo de digestão in vitro, demonstrando, dessa forma, não ser um material adequado para encapsulação e estudos de liberação controlada. Com a mucilagem de inhame, a difusão das células para o meio externo foi gradual até o tempo 120 minutos em $\mathrm{pH} 1,5$ e permaneceu constante até o tempo 30 minutos em pH 5,6. Após esse período, foi evidenciada uma queda de aproximadamente $4,00 \%$ na contagem (Tabela 3). Possivelmente, este desempenho é algo intrínseco da matéria-prima, pois não foi evidenciado este padrão com as demais mucilagens como materiais encapsulantes. A liberação média do microrganismo durante o processo foi de aproximadamente $84,00 \%$, isto é, reteve $16,00 \%$ do material encapsulado no interior da matriz de encapsulação, apresentando efeitos superiores se comparados com os demais resultados acima citados. Já a mucilagem de quiabo propiciou a menor média de liberação quando comparada aos demais avaliados, como demonstra a Tabela 3. A difusão das células, analisadas estatisticamente $(p<0,05)$, foi gradual até os 120 minutos em $\mathrm{pH} 1,5$, período em que atingiu o ponto máximo de liberação. A mucilagem conferiu a peculiaridade de liberar o menor número de células no início da digestão in vitro $(54,73 \%)$, que é o período mais crítico, e manteve-se deste modo durante todo o processo. A retenção de células no interior da matriz foi de $33,00 \%$, evidenciando uma melhora de aproximadamente $25,00 \%$ quando comparada ao tratamento controle. Portanto, a mucilagem de quiabo demonstra ser um material encapsulante alternativo natural e mais eficiente do que as gomas comumente usadas no mercado.

\subsection{Digestão in vitro de todos os tratamentos: uma visão geral}

De modo geral, dois tratamentos adicionados de mucilagens apresentaram melhores efeitos quando comparados aos tratamentos com gomas, sendo QUI o tratamento que apresentou melhores efeitos. Esses resultados indicam que as mucilagens podem ser os materiais encapsulantes do futuro, com um vasto mercado a ser explorado. Nos diferentes períodos avaliados, foram encontradas várias diferenças estatísticas entre os tratamentos, porém, os tratamentos QUI, LIN e ALG prevaleceram como os melhores retentores de microrganismo na matriz de encapsulação durante todo o processo, obedecendo à seguinte ordem crescente de liberação: $Q U \mid<L I N<A L G<I N H<A R A<I-C A R<-A-A<T A R O$. Ding e Shah (2009) encapsularam microrganismos dos gêneros Lactobacillus e Bifidobacterium em diferentes materiais encapsulantes (goma xantana, guar e locusta, alginato de sódio e carragena) a uma concentração de 3,00 \% pelo método de emulsão. Após simulação gastrointestinal in vitro, concluíram que, em ordem crescente de viabilidade, a goma xantana, a carragena e o alginato de sódio apresentaram os melhores resultados.

\subsection{Microscopia eletrônica de varredura das matriz de encapsulação}

Foi possível visualizar com clareza o envolvimento completo do microrganismo pela matriz, como demonstrado na Figura 1, em cujas imagens com aumentos de 20.000, 10.000 e 5.000 vezes se observou um sistema de "colmeias" que aprisionaram a levedura no meio encapsulante, tornando presumível a existência de uma proteção física às células por meio dos materiais 

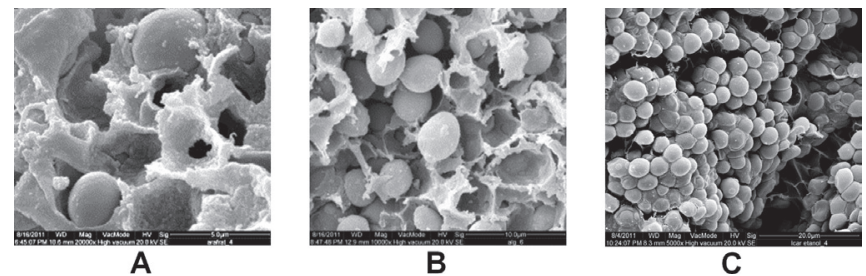

Figura 1. Microscopia eletrônica de varredura da matriz de encapsulação composta de ágar-ágar e gomas comerciais com um aumento de A - 20.000 vezes (ARA); B - 10.000 vezes (ALG); C - 5.000 vezes (I-CAR).

encapsulantes, naturais e comerciais, juntamente com $4 \%$ de ágar-ágar.

$\mathrm{Na}$ tentativa de diferenciar as matrizes pela microscopia eletrônica, foram preparadas cápsulas com e sem o probiótico, em diferentes aumentos, demonstradas na Figura 2. Porém, não foi possível encontrar diferenças visíveis entre os materiais encapsulantes por meio das imagens. Em todos os tratamentos, foi possível observar a presença de poros de tamanhos distintos em toda a
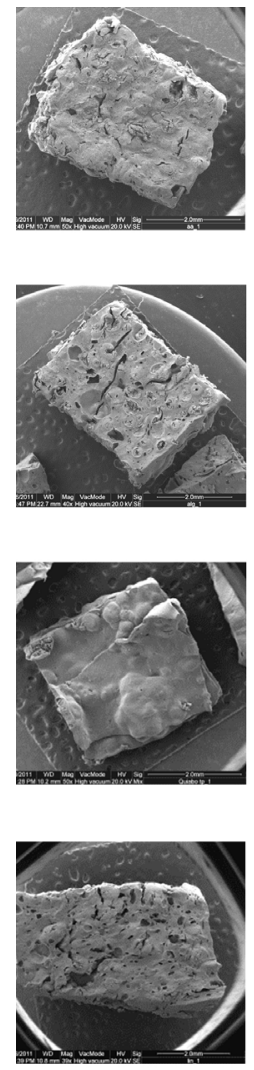

A

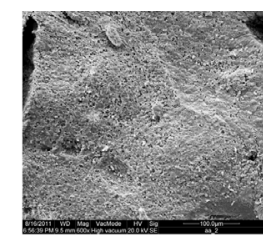

A-A

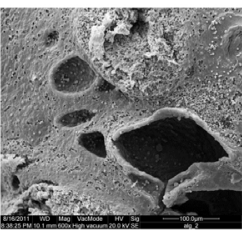

ALG

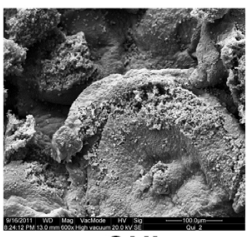

QUI

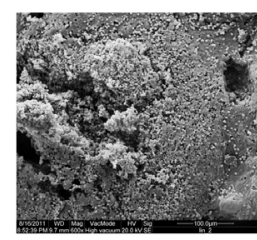

LIN
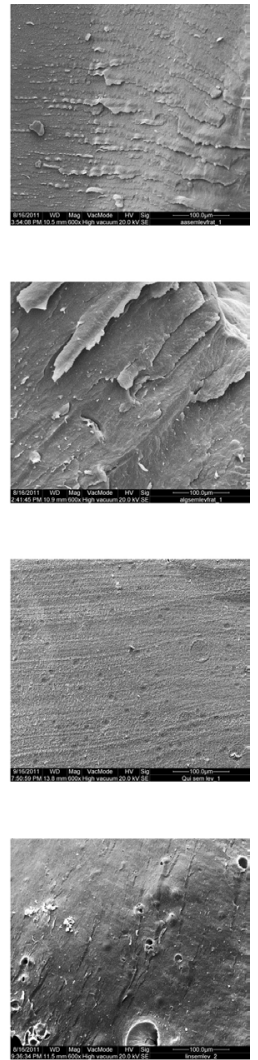

C
Figura 2. Microscopia eletrônica de varredura dos tratamentos compostos por ágar-ágar (A-A) adicionados de alginato de sódigo (ALG), mucilagem de quiabo (QUI) e mucilagem de linhaça (LIN), sendo nas colunas: A - aumento de 50 vezes com levedura; B - aumento de 600 vezes com levedura; C - aumento de 600 vezes sem levedura. extensão da matriz de encapsulação, o que pode ter sido ocasionado pela produção de gás pelas leveduras durante o processo de encapsulação até o período de secagem, pois nas cápsulas produzidas sem a levedura (Figura 2, coluna C) não foram encontrados orifícios.

A grande quantidade de fissuras pode ter influenciado a liberação do microrganismo da cápsula, o que pode explicar a alta difusão de microrganismos para o meio externo logo no início da digestão in vitro, além da influência do pH ácido. Segundo Santos et al. (2005), a presença de poros e fissuras pode comprometer a eficiência da microencapsulação como barreira; entretanto, este problema pode ser resolvido por meio da aplicação de uma segunda cobertura externa sobre a matriz. O ideal seria obter paredes contínuas, uniformes, sem fissuras, rachaduras ou rompimentos, o que é fundamental para garantir uma menor permeabilidade a gases e maior proteção e retenção do recheio. Outros fatores também podem influenciar no controle da taxa de liberação de um agente bioativo, como: a expansão do volume de microcápsulas, em razão da hidratação, a permeabilidade da cápsula, da área de superfície em contato com o meio aquoso, e a concentração intracapsular do agente diluído dentro da cápsula, explica Correa (2003). Através da microscopia eletrônica de varredura, foi possível concluir que não existem diferenças visuais entre as microfotografias de todos os tratamentos, sejam compostos por gomas ou mucilagens. Porém, todos apresentaram uma proteção física, por meio do material encapsulante, conferida às leveduras. Outro fator importante foi a presença de poros e fissuras encontrados nas superfícies da matriz de encapsulação, que poderiam provocar uma difusão rápida das células para o meio externo, assim como a influência da quantidade de agente encapsulante utilizado e o intumescimento da cápsula em meio aquoso.

\section{Conclusões}

Da matriz de encapsulação obtidas com diferentes materiais encapsulantes, a mucilagem de quiabo mostrou-se mais eficiente na retenção do agente encapsulado durante a simulação gastrointestinal in vitro em relação aos demais tratamentos, sendo o alginato de sódio o melhor resultado entre as matrizes de gomas comerciais.

\section{Agradecimentos}

Ao CNPq, pela Bolsa concedida.

\section{Referências}

AINSLEY REID, A.; VUILLEMARD, J. C.; BRITTEN, M.; ARCAND, Y.; FARNWORTH, E.; CHAMPAGNE, C. P. Microentrapment of probiotic bacteria in a $\mathrm{Ca}^{2+}$-induced whey protein gel and effects on their viability in a dynamic gastro-intestinal model. Journal 
Eficiência de materiais encapsulantes naturais e comerciais na liberação controlada de probiótico encapsulado LAURENTI, E. e GARCIA, S.

of Microencapsulation, Quebec, v. 22, n. 6, p. 603-619, 2005. http://dx.doi.org/10.1080/02652040500162840

ANNAN, N. T.; BORZA, A. D.; TRUELSTRUP, L. H. Encapsulation in alginate-coated gelatin microspheres improves survival of the probiotic Bifidobacterium adolescentis 15703T during exposure to simulated gastro-intestinal conditions. Food Research International, Nova Scotia, v. 41, n. 2, p. 184-193, 2008. http:// dx.doi.org/10.1016/j.foodres.2007.11.001

BEHERA, S.; KAR, S.; MOHANTY, R. C.; RAY, R. C. Comparative study of bio-ethanol production from mahula (Madhuca latifolia L.) flowers by Saccharomyces cerevisiae cells immobilized in agar agar and Ca-alginate matrices. Applied Energy, Orissa, v. 87, p. 96-100, 2010. http://dx.doi.org/10.1016/j. apenergy.2009.05.030

CHANG, H. N.; SEONG, G. H.; YOO, I. K.; PARK, J. K.; SEO, J. H. Microencapsulation of recombinant Saccharomyces cerevisiae cells with invertase activity in liquid-core alginate capsules. Biotechnology and Bioengineering, Taejon, v. 51, p. 157-62, 1996.

CORREA, R. M. Preparo e Caracterização de Microcápsulas Obtidas por Polimerização lônica para Alimentação de Larvas de Peixe. 2003. 172 f. Dissertação (Mestrado em Alimentos e Nutrição)-Universidade Estadual de Campinas, Campinas, 2003.

DESMOND, C.; ROSS, R. P.; O'CALLAGHAN, E.; FITZGERALD, G.; STANTON, C. Improved survival of Lactobacillus paracasei NFBC 338 in spray-dried powders containing gum acacia. Journal of Applied Microbiology, Cork, v. 93, p. 10031011, 2002. http://dx.doi.org/10.1046/j.1365-2672.2002.01782.x

DING, W. K.; SHAH, N. P. Effect of Various Encapsulating materials on the stability of probiotic bacteria. Journal of Food Science, Victoria, v. 74, n. 2, p. M100-M107, 2009. http://dx.doi. org/10.1111/j.1750-3841.2009.01067.x

DZIEZAK, J. D. Microencapsulation and encapsulated ingredients. Food Technology, Chicago, v. 42, n. 4, p. 136-151, 1988.

FAVARO-TRINDADE, C. S.; PINHO, S. C.; ROCHA, G. A. Revisão: Microencapsulação de ingredientes alimentícios. Brazilian Journal of Food Technology, Campinas, v. 11, n. 2, p. 103-112, 2008.

FULLER, R. Probiotics in man and animals. Journal Applied Bacteriology, Shinfield, v. 66, p. 55-61, 1989.

GEORGE, M.; ABRAHAM, T. E. Polyionic hydrocolloids for the intestinal delivery of protein drugs: Alginate and chitosan - a review. Journal of Controlled Release, Trivandrum, v. 114, n. 1, p. 1-14. 2006.
GLICKSMAN, M. Gum Technology in Food industry. New York: Academic Press, 1969. p. 11-16.

GRANGEIRO, M. G. A.; FUENTES, M. F. F.; FREITAS, E. R.; ESPÍNDOLA, G. B.; SOUZA, F. M. Inclusão da levedura de canade-açúcar (Saccharomyces cerevisiae) em dietas para frangos de corte. Revista da Sociedade Brasileira de Zootecnia, Fortaleza, v. 30, n. 3, p. 766-73, 2001. http://dx.doi.org/10.1590/ S1516-35982001000300023

GUILLOU, S.; BESNARD, V.; EL MURR, N.; FEDERIGHI, M. Viability of Saccharomyces cerevisiae cells exposed to low-amperage electrolysis as assessed by staining procedure and ATP content. International Journal of Food Microbiology, Nantes, v. 88, n. 1, p. 85-89, 2003. http://dx.doi.org/10.1016/ S0168-1605(03)00112-0

LIMA, G. J. A. Uso de Polímero Natural do Quiabo como Auxiliar de Floculação e Filtração em Tratamento de Água e Esgoto. 2007. 113 f. Dissertação (Mestrado em Engenharia Sanitária e do Meio Ambiente)-Universidade do Estado do Rio de Janeiro, Rio de Janeiro, 2007

LISERRE, A. M.; RÉB, M. I.; FRANCOA, B. D. G. M. Microencapsulation of Bifidobacterium animalis subsp. lactis in Modified Alginate-chitosan Beads and Evaluation of Survival in Simulated Gastrointestinal Conditions. Food Biotechnology, São Paulo, v. 21, p. 1-16, 2007. http://dx.doi. org/10.1080/08905430701191064

OKOJIE, V. U.; OSUIDE, M. O.; AIGBOKHIAN, A. A Study of Some Physico-chemical Characteristics of Cashew Tree Exudate Anacardium Occidentale. Advances in Natural and Applied Sciences Research, Ekpoma, v. 8, p. 259-263, 2010.

PENNACCHIA, C.; BLAIOTTA, G.; PEPE, O.; VILLANI, F. Isolation of Saccharomyces cerevisiae Strains from Different Food Matrices and their Preliminary Selection for a Potential Use as Probiotics. Journal of Applied Microbiology, Portici, v. 105, n. 6, p. 1919-1928, 2008.

RAJKOWSKA, K.; KUNICKA-STYCZYNSKA, A. Probiotic properties of yeasts isolated from chicken feces and kefirs. Polish Journal of Microbiology, Lódz, v. 59, n. 4, p. 257-63, 2010.

RUIZ, J. N. Aplicação de Microrganismos Probióticos nas Formas Livre e Microencapsulada em Salame Tipo Italiano. 2011. 123 f. Dissertação (Mestrado em Ciências)-Escola Superior de Agricultura "Luiz de Queiroz", Piracicaba, 2011.

SANTOS, A. B.; FAVARO-TRINDADE, C. S.; GROSSO, C. R. F. Preparo e caracterização de microcápsulas de oleoresina de páprica obtidas por atomização. Ciência e Tecnologia de Alimentos, Campinas, v. 25, n. 2, p. 322-326, 2005. http://dx.doi. org/10.1590/S0101-20612005000200024 